\title{
Assessment of means of mechanization of construction risks using catastrophe theory
}

\author{
Vladimir Zorin ${ }^{1, *}$ and Natali Baurova ${ }^{1}$ \\ ${ }^{1}$ Moscow Automobile and Road Construction State Technical University, Russia
}

\begin{abstract}
In article questions of assessment of the risks arising in the course of design, production and operation of means of mechanization of construction using catastrophe theory are considered. In the course of operation of the machine malfunctions, suddenly defiant refusals of details gradually collect. The device of the theory of accidents allows to develop models of change of technical condition and operational properties of a details material for various service conditions. In the field of space of conditions of the system containing critical signs accident emergence conditions (refusal of a detail and an emergency) are created. Assessment of probability of emergence of refusal during a certain period of operation of the machine taking into account weight of consequences allows to establish risk level.
\end{abstract}

\section{Introduction}

Operation of means of construction mechanization is connected with risk of emergence of an emergency capable to lead both to material losses, and to the human victims $[1,2,3,4]$. The risk represents a combination of probability of emergence of refusal and weight of damage from this event. Modern international requirements to systems of quality management of the enterprises [GOST P ISO 31000-2010 Management of Risk. Principles and management] which are engaged in production, operation and repair of means of mechanization of construction provide need of assessment of risk for decrease in accident rate, probability of emergence of refusals and increase in efficiency of use of machines [3].

The main objectives of assessment of risks are:

- analysis of the reasons and probabilities of loss of working capacity by machine (malfunctions, refusal);

- identification of dangerous events - types and consequences of refusals and emergencies;

- identification of possible refusals of a consequence and emergencies;

- assessment of probability of emergence of refusals and emergencies;

- justification of the actions allowing to reduce adverse effects or to reduce probability of emergence of refusals and emergencies [4,5].

The existing methods of assessment of risks [3] are based on the analysis of information on technical condition, refusals and malfunctions of an object.

\footnotetext{
* Corresponding author: madi-dm@list.ru
} 


\section{Methods}

Means of mechanization of construction from the point of view of assessment of risks, reliability and safety, are quite difficult mechanical systems. Therefore it is impossible to make rather full calculations and assessment of risks at design stages and productions.

In article the possibility of application of methods of catastrophe theory at assessment of the risks arising at design, production and operation of means of mechanization of construction is considered. Any product of mechanical engineering in use experiences complex influence of set of various factors. Joint influence of various operational factors exerts not unambiguous impact on kinetics of process of decrease in operability of machines. The majority of damages and malfunctions collect in means of mechanization of construction in the course of work gradually while destruction and refusals happen, as a rule, is unpredictable. Thus, the system makes spasmodic transition from one state to another at smooth change of external conditions and, therefore, for its description it is expedient to use the catastrophe theory. Under accident, according to [1] understand the spasmodic change of parameter arising in the form of the sudden response of system to smooth change of external conditions.

Processes of change of technical condition of means of construction mechanization under operating conditions can be described set of the monotonous nonlinear dependences which do not have pronounced extreme values. For such cases in the catastrophe theory it is accepted as critical to use an inflection point (fig. 1) in which the speed of process of decrease in working capacity $f(x)$ changes, i.e.

$$
\left.\frac{d f}{d x_{i}}\right|_{u}=0 \quad \text { at } i=1, n(1)
$$

The critical dots shown in fig. 1 are structurally steady. In the elementary case function $f(x)$ from one variable has an appearance

$$
f(x)=a \pm b x^{2}
$$

In the equation (2) signs \pm characterize accessory of processes of change of technical condition of the machines to various regularities. For example, if to consider processes of change of strength properties of machines details in use, the $\mathrm{f}(\mathrm{x})$ function is decreasing (fig. 1, a curve 1). If to consider process of change of residual tension in the course of degradation of operational properties of materials of machines details, the $f(x)$ function has an appearance increasing (fig. 1, a curve 2).

In fig. 1 examples of functions from one variable (are given at $n=1$ ). In the presence of several factors defining the nature of function more difficult dependences are used. As such variable the indicator of speed of decrease in operability of $v$ can be used. 


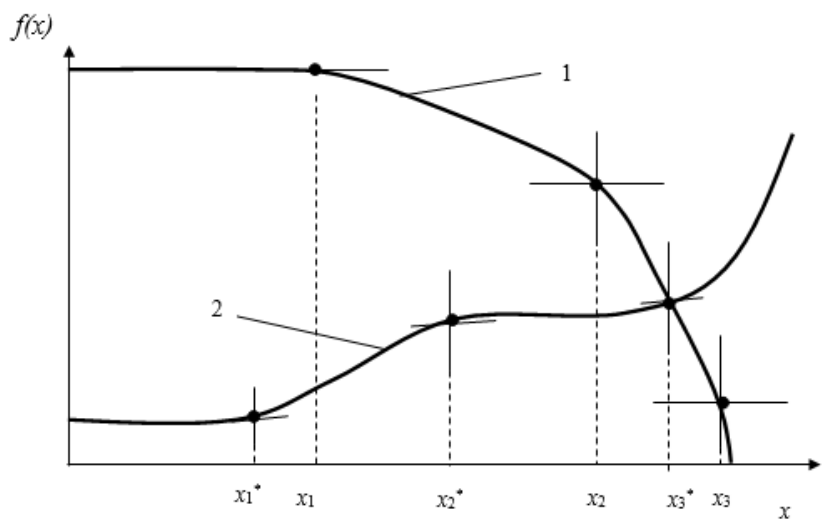

Fig. 1. Tipe of critical dots: $n=1: 1$ - the function $f(x)$ decreases; 2 - the function $f(x)$ increases.

Typical regularity of change of speed of decrease in operability of the machine can be presented by analogy with a curve of the speed of wear given on fig. 2 . In this case it is possible to allocate 3 stages of process: 1-intensive increase of speed of decrease in working capacity (intensity of emergence of refusals) characteristic of the period extra earnings of machines details; 2 stage of normal operation; 3 stage of catastrophic decrease in working capacity [3].

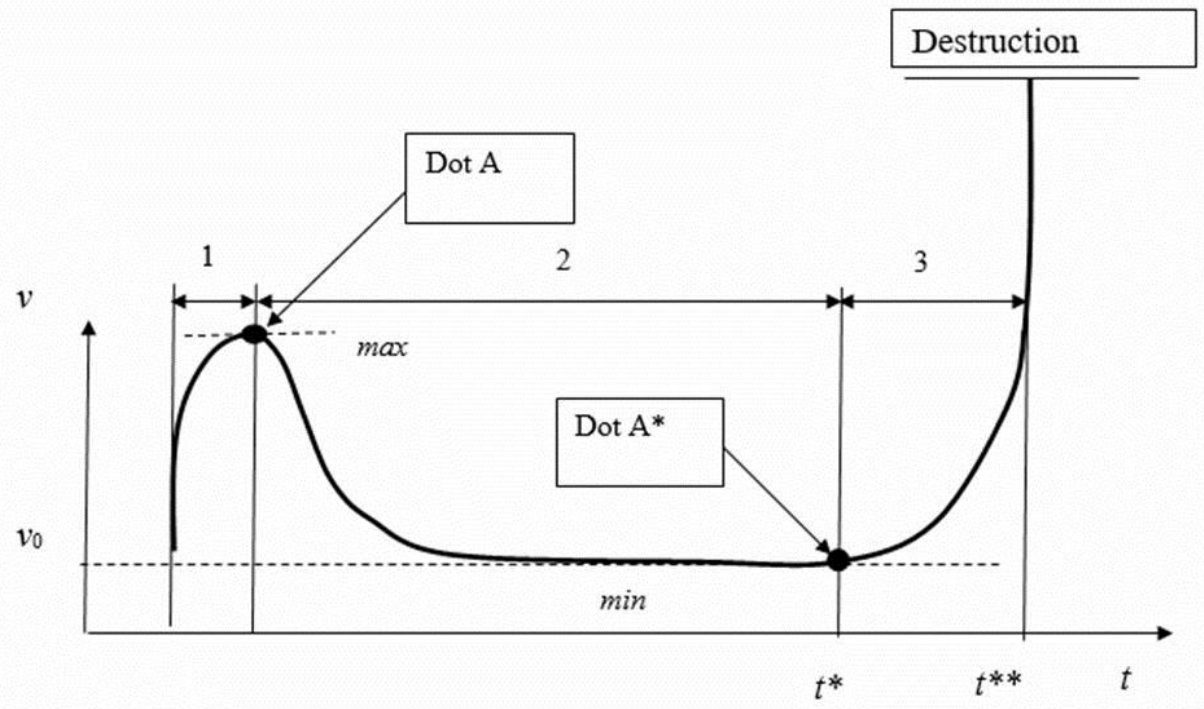

Fig. 2. Scheme of change of speed of decrease in operability of a detail of $V$ from time $t$.

At the first stage of value of speed of decrease in operability of machines not linearly grow and pass through a maximum. This maximum value $v$ can be also used as a critical point when machinerying out calculations with use of catastrophe theory.

Stabilization of technical condition of system and gradual decrease in its working capacity during the long period of operation of a product of mechanical engineering is characteristic of the second stage. 
At the third stage there is a "catastrophic" decrease in operability of the machine preceding destruction of details and emergence of an emergency. The point allocated for fig. 2 in the field of $\min$ is used as catastrophe theory, critical at creation of models, as in this point the system is in unstable state [9].

Thus, when developing models of stability of technical condition of products of mechanical engineering physical models of two types can be used: $1)$;

- the first, private, describing processes of decrease in operability of the machine (fig.

- the second, the general, (fig. 2) allowing to investigate processes of change of durability of machines details, describing processes of change of speed of decrease in operability of products of mechanical engineering under operating conditions [8].

\section{Models}

Models of change of technical condition and operational properties of material of a detail in the conditions of standard loading are given in fig. 3. As initial functions of a state dependences of change of a limit condition of material of detail on functions of two variables are used: deformations and temperatures. The combination of fragile and fatigue failure of material of a detail describes area of space of states $R^{n}$ in which at a given time there will be a destruction (i.e. accident of $M$ ).

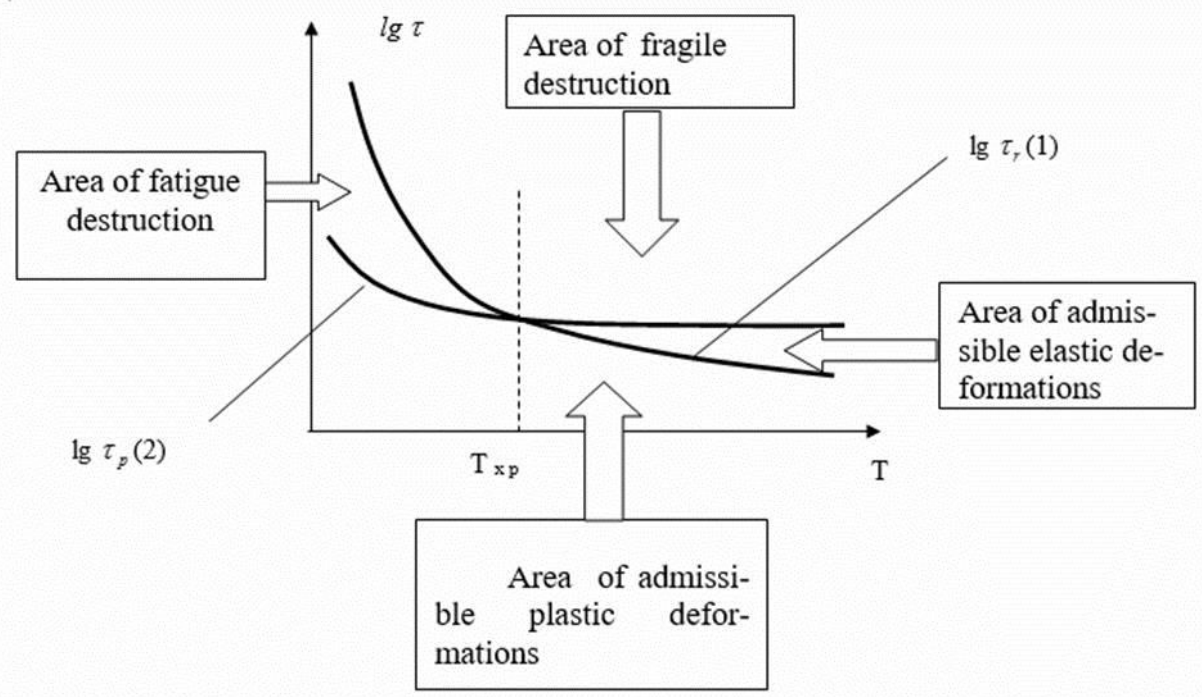

Fig. 3. The scheme of dependence of time before $\tau_{p}$ destruction (2) and time $\tau_{r}$ of relaxation (1) of details material from temperature at a constant tension

In two other (fig. 3) areas - admissible plastic deformations and admissible elastic deformations by criterion of fatigue of destruction of material of a detail at the set tension and temperatures do not happen. We will call these areas space of deformations $R^{r}$.

Catastrophe (for the reviewed example is a destruction of details material) will take place in that area of space where there is a change of quantity and the nature of critical points $[5,6,7]$. 
The nature of change of operational properties of details material depends on the speed of development of processes of destruction and a relaxation. At a tension $\tau_{i}<\tau_{x p}$ processes of a relaxation significantly advance processes of a rupture of communications and in material there is an alignment of tension in places of their concentration and takes place, socalled, deformation hardening. At a tension $\tau_{i}>\tau_{x p}$ process of destruction advances processes of a relaxation with continuous acceleration that leads to destruction of material and refusal of a detail (accident).

According to R. Thoma $[1,2]$ theorem it is accepted that the l-parametrical family of smooth functions $L^{n} \rightarrow L$ for any $n$ and $l$ is structurally steady and equivalent near any noncritical $u_{1}$ and not expressed critical $u_{1}^{2}$ point.

These types $u_{1} \quad u_{1}^{2}$ are also not forms of accidents as do not depend on $t$ time. All subsequent forms will already be accidents. In Arnold [2] classification they have the following names:

fold (A2)

$$
u_{1}^{3}+t_{1} u_{1}+(M)
$$

assembly (A3)

$$
\pm\left(u_{1}^{4}+t_{2} u_{2}^{2}+t_{1} u_{1}\right)+(M) ;
$$

larkspur (A4)

$$
u_{1}^{5}+t_{3} u_{1}^{3}+t_{2} u_{2}^{2}+t_{1} u_{1}+(M) ;
$$

butterfly (A5)

$$
\pm\left(u_{1}^{6}+t_{4} u_{1}^{4}+t_{3} u_{1}^{3}+t_{2} u_{1}^{2}+t_{1} u_{1}+(M) ；\right.
$$

wigwam (A6)

$$
u_{1}^{7}+t_{5} u_{1}^{5}+t_{4} u_{1}^{4}+t_{3} u_{1}^{3}+t_{2} u_{1}^{2}+t_{1} u_{1}+(M) \text {. }
$$

Above and above the given functions belong to the class of kaspoidny accidents.

Accident of a fold is the simplest of the models allowing to describe the processes of decrease in operability of a product of mechanical engineering presented in fig. 1 and 2 . Standard regularity (when using accident of a fold) according to [2] is set by a formula

$$
L(u)=\frac{1}{3} u^{3}+t_{1} u
$$

The variety of accidents of $M$ is defined by the equation

$$
0=\frac{d}{d u} L_{x}(u)=u^{2}+t_{1}
$$

As the map for $M$ according to the equation (4) we set $u$ coordinate

$$
\left(u, t_{1}\right)=\left(u,-u^{2}\right) .
$$

\section{Results}

The variety of accidents represents a parabola (see fig. 4) which bifurcation set consists of one point. The critical conditions of system designated $\min L(u)$ and $\max L(u)$, settle down in the left part of the schedule. 


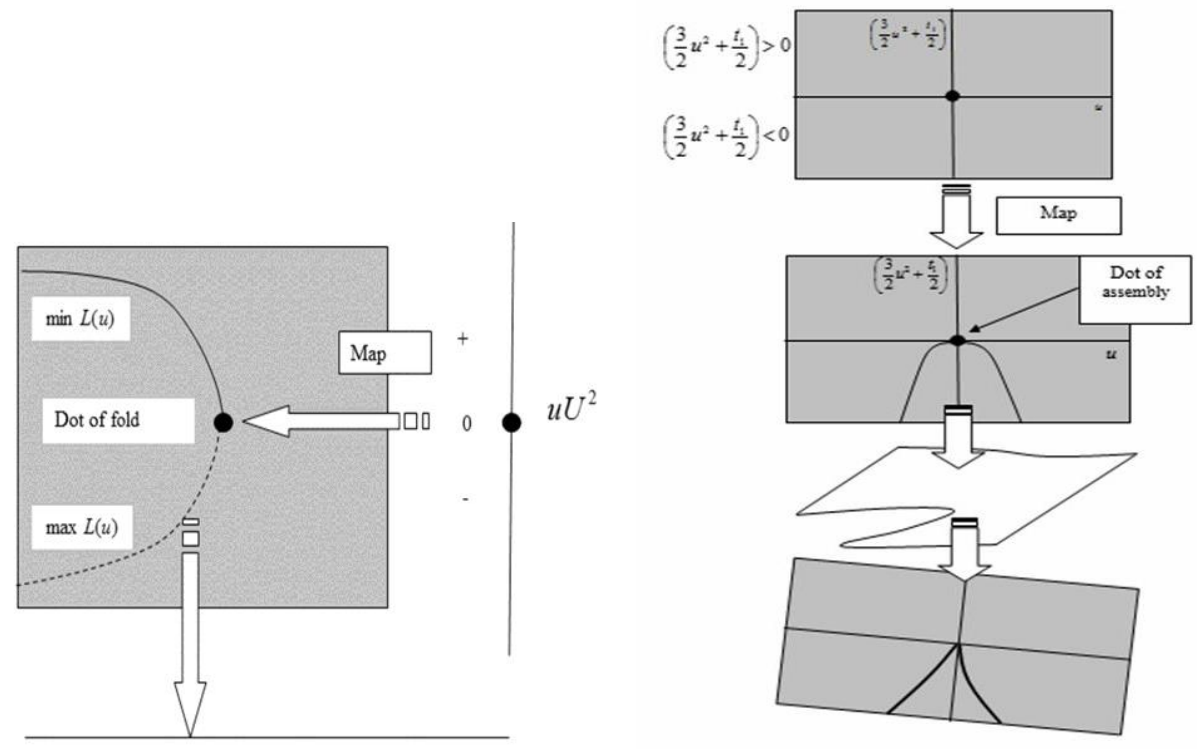

Fig. 4. Fold catastrophe and assembly catastrophe geometry

Accident will happen in timedot $t^{*}<t^{* *}$ at which sizes of speed of decrease in operability of $v$ (see fig. 2) will reach maximum permissible value.

When using the catastrophe theory, serves as the standard regularity describing decrease in operability of the machine

$$
L(u)=\frac{1}{3} u_{1}^{4}+\frac{1}{2} t_{2} u_{2}^{2}+t_{1} u_{1}
$$

and the variety of accidents is set by the equation

$$
0=\frac{d}{d u} L(u)=u^{3}+u t_{1}+t_{2} .
$$

As map parameters for $\mathrm{M}$ we set coordinates

$$
\left(u, t_{1}, t_{2}\right)+\left(u, t_{1},-u t_{1}-u^{3}\right),
$$

and then this map registers as follows

$$
L^{2} \rightarrow M,\left(u, t_{1}\right) \Rightarrow\left(u, t_{1},-u t_{1}-u^{3}\right)
$$

The example of catastrophe assembly geometry is shown in fig. 4. This model allows to describe processes of change of operability of the machine in various service conditions taking into account a set of the defining factors.

\section{Discussion}

Basis for assessment of risks $R$ means of construction mechanization are the functionality of $F$ connecting probability $P$ emergence of an adverse event (malfunction, refusal), and population mean of damage of $U$ from this adverse event: 


$$
R=F_{R}\{U, P\}=\sum_{i}\left[F_{R}\left(U_{i}, P_{i}\right)\right]=\int C(U) P(U) d U=\int C(P) U(P) d P,
$$

where $i$ - types of adverse events (malfunctions, refusals);

$C$ - the weight functions considering mutual influence of risks.

Assessment of weight of estimated consequences of emergence of refusal is made by standard methods of the engineering, technical and economic analysis.

\section{Conclusions}

The reviewed examples of models of processes of change of a condition of mechanical system do not exhaust all opportunities of use catastrophe theory for forecasting of working capacity and assessment of risks at design, production and operation of means of side.

\section{References}

1. V.A. Ostreykovsky Analysis of stability and controllability of dynamic systems by methods of the theory of accidents: (M.: Vyssh. Sc., 2005)

2. V. I. Arnold Theory of accidents, (M: Editorial of URSS, 2007)

3. V. A. Zorin, Nadyozhnost of mechanical systems M: INFRA-M publishing house, (M: INFRA-M, 2015)

4. V. A. Zorin, K. YU. Kim, J Gr. Mag., 9, (2016)

5. N. I. Baurova, V. A. Zorin, V. M. Prikhodko, Theor. foundations of chem. eng., 50, 1, (2016)

6. N. I. Baurova, V. A. Zorin, V. M. Prikhodko, Pol. Sc., Ser. D. 9, 2 (2016)

7. N. I. Baurova, V. A. Zorin, V. M. Prikhodko, Pol. Sc., Ser. D. 9, 4 (2016)

8. G. V. Malysheva, I. K. Romanov, Repair, rest., modern., 6 (2015)

9. L. G. Petrova, O. V. Chudina, Metal Sc. and Heat Treat., 52, 5-6 (2010)

10. N. I. Baurova Polym. Sci., Ser. D 2 (2), 130-132 (2009).

11. Yu. I. Boitsov and T. A. Guzeva ," Klei, Germetiki, Tekhnol.,No. 4, 34-35 (2005).

12. V. A. Nelyub and A. A. Berlin, Khim. Volokna, No. 5, 30-35 (2014).

13. I. A. Aleksandrov, G. V. Malysheva, et al., Vse Mater. Entsikl. Spravochnik, No. 3, 7 12 (2012).

14. V. A. Nelyub, I. A. Aleksandrov, et al., Entsikl. Inzh.-Khim., No. 5, 34-38 (2013).

15. A. N. Muranov, G. V. Malysheva, et al., Polym. Sci., Ser. D, 6, No. 3, 256-259 (2013).

16. N. S. Sevryugina, E. A. Volkov, E. P. Litovchenko, Modern Applied Science 8(5), (2014)

17. N. Sevryugina, MATEC Web of Conferences, 117, 00151 (2017) 